\title{
Mediterranean diet and CHD: the Greek European Prospective Investigation into Cancer and Nutrition cohort
}

\author{
Vardis Dilis ${ }^{1,2}$, Michail Katsoulis ${ }^{1,2}$, Pagona Lagiou ${ }^{1,3,4}$, Dimitrios Trichopoulos ${ }^{3,4}$, Androniki Naska ${ }^{1,2}$ \\ and Antonia Trichopoulou ${ }^{1,2_{*}}$ \\ ${ }^{1}$ Department of Hygiene, Epidemiology and Medical Statistics, WHO Collaborating Center for Food and Nutrition Policies, \\ University of Athens Medical School, 75 Mikras Asias Street, GR-11527 Athens, Greece \\ ${ }^{2}$ Hellenic Health Foundation, 13 Kaisareias and Alexandroupoleos Street, GR-11527, Athens, Greece \\ ${ }^{3}$ Department of Epidemiology, Harvard School of Public Health, 677 Hurtington Street, Boston, MA O2115, USA \\ ${ }^{4}$ Bureau of Epidemiologic Research, Academy of Athens, 28 Panepistimion Street, GR-10679 Athens, Greece \\ (Submitted 17 October 2011 - Final revision received 20 February 2012 - Accepted 24 February 2012 - First published online 4 July 2012)
}

\section{Abstract}

Adherence to the Mediterranean diet (MD) has been reported to improve CHD prognosis and to be inversely associated with CHD mortality. The aim of the present study was to investigate the association of adherence to the MD with CHD incidence and mortality in the Greek European Prospective Investigation into Cancer and Nutrition cohort, a population with traditional Mediterranean roots. In a general population sample of 23929 adult men and women with no CVD or cancer at enrolment, a validated FFQ was interviewer-administered, sociodemographic, physical activity and other characteristics were recorded, and arterial blood pressure and anthropometric characteristics were measured. In a median period of 10 years, 636 incident CHD cases and 240 CHD deaths were recorded. Associations of adherence to the MD, operationalised through a nine-component score (0, poor; 9, excellent), with CHD incidence and mortality were evaluated through Cox regression controlling for potentially confounding variables. A two-point increase in the MD score was associated with lower CHD mortality by $25 \%$ (95\% CI $0.57,0.98)$ among women and $19 \%$ (95\% CI $0.67,0.99)$ among men. The association of adherence to the MD with CHD incidence was again inverse, but weaker (hazard ratios 0.85 (95\% CI 0.71, 1.02) among women and 0.98 (95\% CI 0.87, $1 \cdot 10$ ) among men). With respect to score components, only meat among men (positively) and fruits and nuts among women (inversely) were associated with both the incidence of and mortality from CHD. The MD, as an integral entity, is inversely associated with CHD incidence and, particularly, mortality.

Key words: Mediterranean diet: CHD: European Prospective Investigation into Cancer and Nutrition: Greece

In the early 1960s, Ancel Keys introduced the concept of the traditional Mediterranean diet (MD) and reported its strong ecological association with a low incidence of $\mathrm{CHD}$, attributing this association largely to the low content of the MD in saturated lipids $^{(1)}$. About two decades later, the traditional MD pattern drew again the attention of the scientific community ${ }^{(2)}$ and in the mid-1990s, Trichopoulou et al. ${ }^{(3)}$ introduced a scoring concept to assess conformity with the salient characteristics of this diet. Several score variants have since been introduced ${ }^{(4-8)}$ and used in observational studies to assess the relationship between conformity with the MD and various health outcomes, including total mortality ${ }^{(4,6-9)}$, incidence of or mortality from stroke $^{(10)}$, as well as incidence of or mortality from cancer overall $^{(4,7,8,11)}$ and from specific cancer sites ${ }^{(12-15)}$.

With respect to $\mathrm{CHD}$, a condition intimately linked to the diet $^{(16)}$, there have been prospective studies reporting that conformity with the MD is inversely associated with CHD mortality $^{(4,10,17)}$. There has also been at least one randomised trial $^{(18)}$, indicating that a closer adherence to the MD or its key elements may improve CHD prognosis ${ }^{(19,20)}$. Furthermore, three studies have examined the association of conformity with a traditional MD pattern with the incidence of CHD, one in the USA, in the major Nurses' Health Study ${ }^{(10)}$, and two in Spain, notably one in the Spanish component of the European Prospective Investigation into Cancer and Nutrition (EPIC) ${ }^{(21)}$ and the second in the Seguimierto Universtiy of Navarra (SUN) Project cohort ${ }^{(22)}$; they all indicated an inverse association of adherence to the MD with CHD incidence.

We have studied the association of adherence to the MD with the incidence of and mortality from CHD in the Greek component of the EPIC cohort. Greece is one of the countries in which Keys and his colleagues undertook their original

Abbreviations: EPIC, European Prospective Investigation into Cancer and Nutrition; ICD, International Classification of Diseases; MD, Mediterranean diet. 
work, and a Mediterranean country in which large segments of the population still adhere to the traditional MD pattern.

\section{Methods}

\section{Study population}

The EPIC cohort comprises about 520000 participants from twenty-three centres in ten European countries. It provides data on diet, anthropometry, lifestyle, socio-economic variables, as well as genetic and biomarker data in relation to cancer and other chronic diseases ${ }^{(23)}$. The EPIC cohort in Greece consists of 28572 volunteers (11954 men and 16618 women) aged 20-86 years recruited between 1994 and 1999 from all over Greece. Participants were actively followed up through telephone interviews by specially trained health professionals (next of kin interviewed, in the case of death of a participant).

For the present study, of the 28572 Greek volunteers, 3118 subjects with prevalent CVD or cancer at recruitment were excluded. From the remaining subjects, another 1525 were excluded for not having any follow-up data at all as of 31 December 2009 or not having information for one or more of the study variables. Thus, a total of 23929 subjects were included in the present investigation. The procedures implemented in the EPIC study were in accordance with the Declaration of Helsinki on the Ethical Principles for Medical Research involving Human Subjects of 1975 as revised in 1983. All study participants signed an informed consent form and the study protocol was approved by the ethics committees of the International Agency for Research on Cancer and the Medical School of the University of Athens.

\section{Dietary information}

Dietary habits of the study participants were assessed at baseline through a validated interviewer-administered semiquantitative $\mathrm{FFQ}^{(24,25)}$. The FFQ reflected the frequency of consumption of about 200 foods and recipes that are common in Greece. The quantification of dietary intake was performed with the use of photographs of usual portion sizes. Nutrient and energy intakes were estimated through the Greek Food Composition Tables ${ }^{(26)}$.

Conformity with the traditional MD was assessed through a MD score (range 0-9 points), as described by Trichopoulou et $a l^{(4)}$. The score relies on nine dietary components, frequent or less frequent consumption of which is typical of the traditional MD. A value of 0 or 1 is assigned to each component of the score as follows: for components frequently consumed in the traditional MD (vegetables, legumes, fruits and nuts, cereals, fish and seafood, as well a high ratio of monounsaturated:saturated lipids), subjects whose consumption was above the sex-specific median are assigned a value of 1 or 0 otherwise; for components less frequently consumed in the traditional MD (dairy, as well as meat and meat products), subjects whose consumption is equal to or lower than the sex-specific median are assigned a value of 1 or 0 otherwise. A value of 1 is also given to subjects consuming a moderate amount of alcohol (i.e. between 5 and $25 \mathrm{~g} / \mathrm{d}$ for women and between 10 and $50 \mathrm{~g} / \mathrm{d}$ for men) or a value of 0 otherwise. Thus, the total MD score can take values from 0 (minimal adherence to the traditional MD) to 9 (maximal adherence to the traditional MD).

\section{Non-dietary information}

A number of sociodemographic and lifestyle characteristics, including years of schooling, smoking and physical activity, were recorded at enrolment. An overall metabolic equivalent task-h/d index, expressing the average daily energy expenditure level, was calculated on the basis of the frequency and duration of participation in occupational and leisure-time physical activities ${ }^{(27,28)}$. Anthropometric measurements were also undertaken using standardised procedures and allowing for the calculation of BMI $\left(\mathrm{kg} / \mathrm{m}^{2}\right)$. Arterial blood pressure was measured by trained physicians, through a mercury sphygmomanometer (Baumanometer; W.A. Baum Company Inc.) and following international protocols ${ }^{(29)}$. The averages of two readings for both systolic and diastolic blood pressure were used. For the present study, hypertension was defined as systolic blood pressure of $140 \mathrm{mmHg}$ or higher, or a diastolic blood pressure of $90 \mathrm{mmHg}$ or higher, or use of antihypertensive medication.

\section{Study outcomes}

Self-reporting of a CHD event during the follow-up was confirmed through hospital discharge data, medical records or death certificates, and was classified according to the 10th revision of the International Classification of Diseases $(\mathrm{ICD})^{(30)}$. The following three manifestations of CHD were considered: myocardial infarction (ICD-10 codes I21, I22, I23, Z95.1 and I46), angina (ICD-10 code I20) and CHD other than angina or myocardial infarction (ICD-10 codes I24, I25, Z95.5, Z95.8 and Z95.9, which include other acute and chronic IHD, presence of coronary angioplasty implant and graft $)^{(31)}$. For the calculation of CHD incidence, the first CHD event was considered, even if that event was death from CHD. For the calculation of CHD mortality, death from CHD was considered, irrespectively of whether a CHD event had occurred in the past or not.

\section{Statistical analysis}

Statistical analyses were performed using the Stata Statistical Software, release 11 (StataCorp. 2009, StataCorp LP). We calculated sex-specific distributions of the study participants, person-time at risk, incident CHD cases and CHD deaths by participants' personal characteristics (excluding the diet), as well as hazard ratios for CHD incidence and mortality, mutually adjusting for energy and non-nutritional variables. We also calculated daily intakes (means and percentiles) of the key dietary components by sex. Associations between dietary intakes and CHD incidence and mortality were next evaluated through Cox regression. The statistical models were fitted: (1) adjusting only for age and energy intake; 
Table 1. Distribution of the study participants, person-time at risk, incident CHD cases and CHD deaths, and hazard ratios (HR) for CHD incidence and mortality by participants' personal characteristics: the Greek European Prospective Investigation into Cancer and Nutrition cohort - men

(Hazard ratios and $95 \%$ confidence intervals)

\begin{tabular}{|c|c|c|c|c|c|c|c|c|}
\hline & \multirow[b]{2}{*}{ Study participants $(n)$} & \multirow[b]{2}{*}{ Person-years at risk $\dagger$} & \multirow[b]{2}{*}{ Incident CHD cases $(n)$} & \multirow[b]{2}{*}{ CHD deaths $(n)$} & \multicolumn{2}{|c|}{ CHD incidence* } & \multicolumn{2}{|c|}{ CHD mortality* } \\
\hline & & & & & $\mathrm{HR}$ & $95 \% \mathrm{Cl}$ & $H R$ & $95 \% \mathrm{Cl}$ \\
\hline All & 9740 & 89716 & 426 & 150 & & & & \\
\hline \multicolumn{9}{|l|}{ Age (years) } \\
\hline$<45$ & 3511 & 31648 & 50 & 9 & 1.0 & & 1.0 & \\
\hline $45-54$ & 2419 & 22792 & 89 & 16 & $2 \cdot 32$ & $1.62,3.32$ & 1.99 & $0.86,4.61$ \\
\hline $55-64$ & 1975 & 19049 & 115 & 24 & 3.48 & $2.39,5.08$ & 3.04 & $1.31,7.06$ \\
\hline$\geq 65$ & 1835 & 16227 & 172 & 101 & $5 \cdot 69$ & $3.79,8.54$ & 13.75 & $6.03,31.36$ \\
\hline \multicolumn{9}{|l|}{ Years of schooling } \\
\hline$\leq 6$ & 4603 & 42173 & 278 & 124 & 1.0 & & 1.0 & \\
\hline$>6$ & 5137 & 47543 & 148 & 26 & 1.05 & $0.82,1.34$ & 0.64 & $0.39,1.05$ \\
\hline \multicolumn{9}{|l|}{ Height (cm) } \\
\hline$<165$ & 2048 & 18896 & 130 & 61 & 1.0 & & 1.0 & \\
\hline $165-169$ & 2471 & 22713 & 134 & 41 & 1.11 & $0.87,1.42$ & 0.88 & $0.59,1.32$ \\
\hline $170-174$ & 2591 & 24042 & 88 & 31 & 0.88 & $0.66,1.17$ & 0.96 & $0.61,1.50$ \\
\hline$\geq 175$ & 2630 & 24065 & 74 & 17 & 0.99 & $0.72,1.35$ & 0.84 & $0.47,1.49$ \\
\hline \multicolumn{9}{|l|}{ BMI $\left(\mathrm{kg} / \mathrm{m}^{2}\right)$} \\
\hline$<25$ & 1909 & 17572 & 61 & 29 & 1.0 & & 1.0 & \\
\hline$\geq 25$ and $<30$ & 5143 & 47548 & 209 & 68 & 1.26 & $0.95,1.68$ & 0.93 & $0.60,1.45$ \\
\hline$\geq 30$ & 2688 & 24596 & 156 & 53 & 1.58 & $1 \cdot 16,2 \cdot 13$ & $1 \cdot 17$ & $0.73,1.86$ \\
\hline \multicolumn{9}{|c|}{ Physical activity level (MET-h/d) } \\
\hline$<35$ & 5250 & 47392 & 272 & 100 & 1.0 & & 1.0 & \\
\hline$\geq 35$ & 4490 & 42324 & 154 & 50 & 0.83 & $0.68,1.02$ & 0.96 & $0.67,1.37$ \\
\hline \multicolumn{9}{|l|}{ Alcohol intake $(\mathrm{g} / \mathrm{d})$} \\
\hline$<5$ & 2936 & 26519 & 150 & 61 & 1.0 & & 1.0 & \\
\hline$\geq 5$ and $<25$ & 4163 & 38756 & 174 & 50 & 0.85 & $0.68,1.07$ & 0.65 & $0.44,0.95$ \\
\hline$\geq 25$ & 2641 & 24441 & 102 & 39 & 0.75 & $0.57,0.98$ & 0.74 & $0.48,1.15$ \\
\hline \multicolumn{9}{|l|}{ Smoking } \\
\hline Never & 2467 & 23504 & 91 & 33 & 1.0 & & 1.0 & \\
\hline Former smokers & 3048 & 28475 & 144 & 56 & 1.25 & $0.96,1.63$ & 1.35 & $0.88,2.08$ \\
\hline Current smokers & 4225 & 37737 & 191 & 61 & 2.01 & $1 \cdot 56,2 \cdot 61$ & $2 \cdot 22$ & $1.43,3.43$ \\
\hline \multicolumn{9}{|c|}{ Arterial blood pressure } \\
\hline Normal & 5647 & 52372 & 147 & 40 & 1.0 & & 1.0 & \\
\hline High $\ddagger$ & 4093 & 37344 & 279 & 110 & 1.63 & $1 \cdot 30,2 \cdot 03$ & 1.62 & $1.09,2.40$ \\
\hline
\end{tabular}

MET, metabolic equivalent of tasks.

*Mutually adjusted for the variables indicated in the table plus daily energy intake in the following four categories: $<6276 \mathrm{~kJ}(1500 \mathrm{kcal})$; $\geq 6276 \mathrm{~kJ}(1500 \mathrm{kcal})$ and $<8368 \mathrm{~kJ}(2000 \mathrm{kcal})$; $\geq 8368 \mathrm{~kJ}$ (2000 kcal) and $<10460 \mathrm{~kJ}$ $(2500 \mathrm{kcal})$ and $\geq 10460 \mathrm{~kJ}(2500 \mathrm{kcal})$.

†For the CHD incidence analysis.

‡ High blood pressure was defined as systolic blood pressure of $140 \mathrm{mmHg}$ or higher, or diastolic blood pressure of $90 \mathrm{mmHg}$ or higher, or use of antihypertensive medication 
Table 2. Distribution of the study participants, person-time at risk, incident CHD cases and CHD deaths, and hazard ratios (HR) for CHD incidence and mortality by participants' personal characteristics: the Greek European Prospective Investigation into Cancer and Nutrition cohort - women

(Hazard ratios and $95 \%$ confidence intervals)

\begin{tabular}{|c|c|c|c|c|c|c|c|c|}
\hline & \multirow[b]{2}{*}{ Study participants $(n)$} & \multirow[b]{2}{*}{ Person-years at risk $\dagger$} & \multirow[b]{2}{*}{ Incident CHD cases $(n)$} & \multirow[b]{2}{*}{ CHD deaths $(n)$} & \multicolumn{2}{|c|}{ CHD incidence* } & \multicolumn{2}{|c|}{$\mathrm{CHD}$ mortality* } \\
\hline & & & & & $\mathrm{HR}$ & $95 \% \mathrm{Cl}$ & $\mathrm{HR}$ & $95 \% \mathrm{Cl}$ \\
\hline All & 14189 & 140179 & 210 & 90 & & & & \\
\hline \multicolumn{9}{|l|}{ Age (years) } \\
\hline$<45$ & 4539 & 43668 & 5 & 0 & 1.0 & & 1.0 & \\
\hline $45-54$ & 3454 & 35439 & 10 & 3 & 1.0 & & 1.0 & \\
\hline $55-64$ & 3475 & 35363 & 64 & 18 & 5.72 & $3.09,10.59$ & $9 \cdot 26$ & $2 \cdot 54,33 \cdot 80$ \\
\hline$\geq 65$ & 2721 & 25709 & 131 & 69 & $12 \cdot 18$ & $6 \cdot 51,22 \cdot 82$ & $36 \cdot 14$ & $10.02,130.39$ \\
\hline \multicolumn{9}{|l|}{ Years of schooling } \\
\hline$\leq 6$ & 8584 & 84595 & 189 & 82 & $1 \cdot 0$ & & $1 \cdot 0$ & \\
\hline$>6$ & 5605 & 55584 & 21 & 8 & 0.71 & $0.42,1 \cdot 19$ & 0.75 & $0.33,1.71$ \\
\hline \multicolumn{9}{|l|}{ Height (cm) } \\
\hline$<150$ & 1953 & 18977 & 56 & 30 & 1.0 & & $1 \cdot 0$ & \\
\hline $150-154$ & 3577 & 35097 & 82 & 35 & $1 \cdot 19$ & $0.85,1.68$ & 1.00 & $0.61,1.64$ \\
\hline $155-159$ & 4206 & 42192 & 46 & 17 & 0.89 & $0.59,1.32$ & 0.68 & $0.37,1.25$ \\
\hline$\geq 160$ & 4453 & 43913 & 26 & 8 & 0.95 & $0.58,1.55$ & 0.66 & $0.29,1.50$ \\
\hline \multicolumn{9}{|l|}{ BMI $\left(\mathrm{kg} / \mathrm{m}^{2}\right)$} \\
\hline$<25$ & 3567 & 35061 & 22 & 9 & 1.0 & & $1 \cdot 0$ & \\
\hline$\geq 25$ and $<30$ & 5301 & 52699 & 79 & 33 & $1 \cdot 19$ & $0.74,1.92$ & $1 \cdot 20$ & $0.57,2.54$ \\
\hline$\geq 30$ & 5321 & 52419 & 109 & 48 & 1.09 & $0.68,1.76$ & $1 \cdot 14$ & $0.54,2.37$ \\
\hline \multicolumn{9}{|c|}{ Physical activity level (MET-h/d) } \\
\hline$<35$ & 6768 & 65752 & 147 & 70 & 1.0 & & $1 \cdot 0$ & \\
\hline$\geq 35$ & 7421 & 74427 & 63 & 20 & 0.79 & $0.58,1.08$ & 0.62 & $0.37,1.04$ \\
\hline \multicolumn{9}{|l|}{ Alcohol intake $(\mathrm{g} / \mathrm{d})$} \\
\hline$<5 \mathrm{~g} / \mathrm{d}$ & 11046 & 108891 & 184 & 81 & 1.0 & & 1.0 & \\
\hline$\geq 5 \mathrm{~g} / \mathrm{d}$ & 3143 & 31288 & 26 & 9 & 0.77 & $0.50,1.17$ & 0.62 & $0.31,1.26$ \\
\hline \multicolumn{9}{|l|}{ Smoking } \\
\hline Never & 10181 & 101171 & 183 & 78 & 1.0 & & 1.0 & \\
\hline Former smokers & 1121 & 10987 & 10 & 5 & 1.52 & $0.79,2.93$ & 1.92 & $0.75,4.91$ \\
\hline Current smokers & 2887 & 28021 & 17 & 7 & 1.89 & $1 \cdot 10,3.23$ & $2 \cdot 35$ & $1.03,5.34$ \\
\hline \multicolumn{9}{|c|}{ Arterial blood pressure } \\
\hline Normal & 8469 & 84435 & 35 & 16 & 1.0 & & 1.0 & \\
\hline High $\ddagger$ & 5720 & 55844 & 175 & 74 & $2 \cdot 62$ & $1.76,3.90$ & 1.88 & $1.05,3.34$ \\
\hline
\end{tabular}

MET, metabolic equivalent of tasks.

*Mutually adjusted for the variables indicated in the table plus daily energy intake in the following four categories: $<6276 \mathrm{~kJ}(1500 \mathrm{kcal})$; $\geq 6276 \mathrm{~kJ}(1500 \mathrm{kcal})$ and $<8368 \mathrm{~kJ}(2000 \mathrm{kcal})$; $\geq 8368 \mathrm{~kJ}(2000 \mathrm{kcal})$ and $<10460 \mathrm{~kJ}$ $(2500 \mathrm{kcal})$ and $\geq 10460 \mathrm{~kJ}(2500 \mathrm{kcal})$.

† For the CHD incidence analysis.
H igh blood pressure was defined as systolic blood pressure of $140 \mathrm{mmHg}$ or higher, or diastolic blood pressure of $90 \mathrm{mmHg}$ or higher, or use of antihypertensive medication. 
(2) adjusting for age, energy intake and non-nutritional variables; and (3) adjusting for age, non-nutritional variables and other dietary intakes, but excluding total energy intake to avoid collinearity. Continuous non-nutritional variables included in the models were age, years of schooling, height, BMI and physical activity level. Categorical variables included in the models were as follows: smoking status in three categories (never, former or current smokers), levels of arterial blood pressure in two categories (normotensives or hypertensives) and alcohol intake in three categories for men $(<5 \mathrm{~g} / \mathrm{d}$, $\geq 5$ and $<25 \mathrm{~g} / \mathrm{d}$ or $\geq 25 \mathrm{~g} / \mathrm{d}$ ) and two categories for women $(<5 \mathrm{~g} / \mathrm{d}$ or $\geq 5 \mathrm{~g} / \mathrm{d})$. The nutritional variables studied were the components of the MD score (fruits and nuts, vegetables, legumes, cereals, dairy products, meat and meat products, fish and seafood, alcohol and ratio of MUFA:SFA), as well as potatoes, eggs, sweets, non-alcoholic beverages, olive oil, saturated, mono- and polyunsaturated lipids (adjusted as indicated in Tables 4 and 5). Lastly, the association of the MD score (both in categories and as an ordered variable per two-point increment) with CHD incidence and mortality was evaluated by sex and overall (controlling for sex), also controlling for the non-nutritional variables and energy intake.

\section{Results}

Of the study, 636 participants ( 426 males and 210 females) developed CHD in the course of the study. Among them, 240 died from the disease (150 males and ninety females). The follow-up time ranged between 1 month and $15 \cdot 8$ years with a median of 10 years. Tables 1 (men) and 2 (women) present the distributions of participants, person-time at risk, incident CHD cases and CHD deaths by sociodemographic, anthropometric and lifestyle variables, as well as the hazard ratios for CHD incidence and mortality, mutually adjusting for the non-nutritional variables, as well as for alcohol and energy intake. The studied population included more women than men and a high proportion of the participants were of a relatively low education level. The majority of participants of both sexes were either overweight or obese. Most men were light to moderate alcohol drinkers, in contrast to women who largely did not drink alcohol at all. Smoking was very common, particularly among men. The associations of traditional risk factors for CHD with the incidence of and mortality from the disease are evident in the data for the Greek EPIC cohort presented in Tables 1 and 2.

Table 3 presents daily intakes (means and percentiles) of various food groups (including the nine components of the MD score, as well as potatoes, eggs, sweets, non-alcoholic beverages and total energy intake) by sex. The data in this table provide the dietary background of the study population, which still reflects the traditional MD.

Tables 4 (men) and 5 (women) present hazard ratios for the incidence of and mortality from CHD per 1 standard deviation increment of the indicated dietary compounds. Estimates were derived from three models: one controlling for age and energy intake; another also controlling for the non-nutritional variables; a third model in which dietary variables were also mutually adjusted for (without controlling for energy intake). 
Table 4. Hazard ratios (HR) for CHD incidence and mortality from CHD per 1 standard deviation increment for the corresponding nutritional variable: the Greek European Prospective Investigation into Cancer and Nutrition cohort - men

(Hazard ratios and $95 \%$ confidence intervals)

\begin{tabular}{|c|c|c|c|c|c|c|c|c|c|c|c|c|}
\hline \multirow[b]{3}{*}{ Nutritional variables } & \multicolumn{4}{|c|}{ Age and energy intake adjusted ${ }^{\star}$} & \multicolumn{4}{|c|}{$\begin{array}{l}\text { Adjusted for age, energy intake and non-nutri- } \\
\text { tional variablest }\end{array}$} & \multicolumn{4}{|c|}{$\begin{array}{l}\text { Adjusted for age, nutritional and non-nutritional } \\
\text { variablesł }\end{array}$} \\
\hline & \multicolumn{2}{|c|}{$\mathrm{CHD}$ incidence } & \multicolumn{2}{|c|}{$\mathrm{CHD}$ death } & \multicolumn{2}{|c|}{ CHD incidence } & \multicolumn{2}{|c|}{$\mathrm{CHD}$ death } & \multicolumn{2}{|c|}{ CHD incidence } & \multicolumn{2}{|c|}{$\mathrm{CHD}$ death } \\
\hline & $\mathrm{HR}$ & $95 \% \mathrm{Cl}$ & HR & $95 \% \mathrm{Cl}$ & $\mathrm{HR}$ & $95 \% \mathrm{Cl}$ & $\mathrm{HR}$ & $95 \% \mathrm{Cl}$ & $\mathrm{HR}$ & $95 \% \mathrm{Cl}$ & $H R$ & $95 \% \mathrm{Cl}$ \\
\hline Potatoes (g/d) & 1.03 & $0.92,1.14$ & 0.95 & $0.76,1 \cdot 17$ & 1.01 & $0.91,1.13$ & 0.92 & $0.74,1 \cdot 14$ & 1.01 & $0.90,1.13$ & 0.92 & $0.73,1 \cdot 16$ \\
\hline Vegetables (g/d) & $1 \cdot 11$ & $0.98,1.24$ & 0.92 & $0.73,1.17$ & $1 \cdot 12$ & $0.99,1.27$ & 0.96 & $0.75,1.22$ & $1 \cdot 15$ & $0.95,1.39$ & 0.96 & $0.66,1.40$ \\
\hline Legumes $(\mathrm{g} / \mathrm{d})$ & 0.97 & $0.88,1.08$ & 1.02 & $0.85,1.21$ & 0.98 & $0.88,1.08$ & 1.04 & $0.87,1.24$ & 0.96 & $0.86,1.07$ & 1.07 & $0.89,1.29$ \\
\hline Fruits and nuts $(\mathrm{g} / \mathrm{d})$ & 0.90 & $0.79,1.01$ & 0.68 & $0.54,0.87$ & 0.93 & $0.83,1.05$ & 0.73 & $0.57,0.92$ & 0.94 & $0.84,1.06$ & 0.77 & $0.61,0.97$ \\
\hline Dairy foods $(g / d)$ & 0.98 & $0.88,1.09$ & 1.03 & $0.86,1.23$ & 0.99 & $0.88,1.11$ & 1.06 & $0.88,1.27$ & 1.04 & $0.90,1.19$ & 0.93 & $0.73,1.19$ \\
\hline Cereals $(\mathrm{g} / \mathrm{d})$ & 1.01 & $0.90,1.12$ & 0.94 & $0.77,1.15$ & 0.98 & $0.87,1.09$ & 0.91 & $0.74,1 \cdot 11$ & 1.01 & $0.91,1.12$ & 0.95 & $0 \cdot 79,1 \cdot 14$ \\
\hline Meat $(\mathrm{g} / \mathrm{d})$ & $1 \cdot 18$ & $1.05,1.32$ & 1.26 & $1.04,1.54$ & $1 \cdot 13$ & $1.01,1.27$ & $1 \cdot 18$ & $0.96,1.44$ & $1 \cdot 13$ & $1.00,1.27$ & 1.09 & $0.89,1.35$ \\
\hline Fish $(g / d)$ & 1.04 & $0.97,1.12$ & 1.05 & $0.92,1.20$ & 1.03 & $0.95,1.11$ & 1.04 & $0.91,1.20$ & 1.02 & $0.93,1.11$ & 1.05 & $0.90,1.23$ \\
\hline Eggs $(g / d)$ & 1.00 & $0.91,1.10$ & $1 \cdot 12$ & $0.98,1.27$ & 1.00 & $0.91,1.10$ & $1 \cdot 11$ & $0.97,1.26$ & 1.00 & $0.91,1.11$ & 1.10 & $0.97,1.26$ \\
\hline Sugar and confectioneries (sweets) (g/d) & 0.93 & $0.83,1.04$ & 0.85 & $0.69,1.05$ & 0.92 & $0.82,1.03$ & 0.83 & $0.67,1.03$ & 0.94 & $0.83,1.06$ & 0.89 & $0 \cdot 71,1 \cdot 11$ \\
\hline Non-alcoholic beverages $(\mathrm{g} / \mathrm{d})$ & $1 \cdot 11$ & $1.00,1.24$ & 0.95 & $0.76,1.19$ & 1.06 & $0.95,1.18$ & 0.90 & $0.72,1.14$ & 1.08 & $0.97,1.20$ & 0.95 & $0.75,1.21$ \\
\hline Olive oil $(g / d)$ & $1 \cdot 10$ & $0.98,1.23$ & 1.07 & $0.88,1.31$ & 1.09 & $0.97,1.23$ & $1 \cdot 11$ & $0.91,1.36$ & & - & & - \\
\hline Saturated lipids $(\mathrm{g} / \mathrm{d})$ & 1.05 & $0.87,1.26$ & 1.34 & $0.97,1.85$ & 1.00 & $0.82,1.21$ & 1.37 & $0.97,1.95$ & 0.93 & $0.73,1.20$ & 1.39 & $0.89,2 \cdot 15$ \\
\hline Monounsaturated lipids (g/d) & $1 \cdot 14$ & $0.97,1.33$ & 1.05 & $0.80,1.39$ & $1 \cdot 13$ & $0.96,1.34$ & 1.08 & $0.81,1.44$ & 1.01 & $0.76,1.33$ & 0.99 & $0.59,1.68$ \\
\hline Polyunsaturated lipids (g/d) & 0.97 & $0.87,1.08$ & 0.94 & $0.78,1.13$ & 0.97 & $0.87,1.08$ & 0.92 & $0.77,1.11$ & 0.95 & $0.81,1.10$ & 0.90 & $0.69,1.19$ \\
\hline Monounsaturated:saturated lipid ratio & 1.01 & $0.92,1.11$ & 0.93 & $0.79,1.09$ & 1.02 & $0.92,1.12$ & 0.95 & $0.80,1 \cdot 12$ & 0.96 & $0.83,1.12$ & 0.90 & $0.69,1.17$ \\
\hline Energy intake $(\mathrm{kJ} / \mathrm{d})$ & 1.03 & $0.94,1.14$ & 1.06 & $0.89,1.26$ & 1.05 & $0.95,1.17$ & 1.09 & $0.90,1.31$ & & - & & - \\
\hline
\end{tabular}

${ }^{*}$ Age and energy intake entered in the model as continuous variables.

† Age, BMI, height, physical activity, years of schooling and energy intake entered as continuous variables. Alcohol consumption, smoking status and arterial blood pressure entered categorically in the categories indicated in Tables 1 and 2 .

¥Variables as entered in footnote $\dagger$, mutually adjusted for all variables in the table (per 1 standard deviation increment), except olive oil and energy intake that were not included in the model. For the monounsaturated:saturated lipid ratio values, the model was run without controlling for saturated and monounsaturated lipids. 
Table 5. Hazard ratios for (HR) $\mathrm{CHD}$ incidence and mortality from $\mathrm{CHD}$, per 1 standard deviation increment for the corresponding nutritional variable: the Greek European Prospective Investigation into Cancer and Nutrition cohort - women

(Hazard ratios and $95 \%$ confidence intervals)

\begin{tabular}{|c|c|c|c|c|c|c|c|c|c|c|c|c|}
\hline \multirow[b]{3}{*}{ Nutritional variables } & \multicolumn{4}{|c|}{ Age and energy adjusted ${ }^{\star}$} & \multicolumn{4}{|c|}{$\begin{array}{l}\text { Adjusted for age, energy intake and non-nutri- } \\
\text { tional variablest }\end{array}$} & \multicolumn{4}{|c|}{$\begin{array}{l}\text { Adjusted for age, nutritional and non-nutritional } \\
\text { variables } \ddagger\end{array}$} \\
\hline & \multicolumn{2}{|c|}{$\mathrm{CHD}$ incidence } & \multicolumn{2}{|c|}{ CHD death } & \multicolumn{2}{|c|}{$\mathrm{CHD}$ incidence } & \multicolumn{2}{|c|}{$\mathrm{CHD}$ death } & \multicolumn{2}{|c|}{ CHD incidence } & \multicolumn{2}{|c|}{$\mathrm{CHD}$ death } \\
\hline & $\mathrm{HR}$ & $95 \% \mathrm{Cl}$ & $\mathrm{HR}$ & $95 \% \mathrm{Cl}$ & $\mathrm{HR}$ & $95 \% \mathrm{Cl}$ & $\mathrm{HR}$ & $95 \% \mathrm{Cl}$ & $\mathrm{HR}$ & $95 \% \mathrm{Cl}$ & $\mathrm{HR}$ & $95 \% \mathrm{Cl}$ \\
\hline Potatoes (g/d) & $1 \cdot 12$ & $0.91,1.39$ & 1.29 & $0.94,1.77$ & $1 \cdot 11$ & $0.89,1.38$ & 1.29 & $0.93,1.78$ & 1.02 & $0.81,1.29$ & 1.15 & $0.82,1.61$ \\
\hline Vegetables (g/d) & $1 \cdot 10$ & $0.88,1.36$ & $1 \cdot 17$ & $0.84,1.63$ & $1 \cdot 10$ & $0.87,1.38$ & $1 \cdot 17$ & $0.83,1.66$ & 0.89 & $0.62,1.29$ & 1.00 & $0.56,1.78$ \\
\hline Legumes $(\mathrm{g} / \mathrm{d})$ & 0.89 & $0.72,1.09$ & 0.86 & $0.61,1 \cdot 19$ & 0.88 & $0.71,1.09$ & 0.85 & $0.61,1 \cdot 19$ & 0.83 & $0.67,1.03$ & 0.78 & $0.56,1.10$ \\
\hline Fruits and nuts $(\mathrm{g} / \mathrm{d})$ & 0.63 & $0.50,0.79$ & 0.60 & $0.42,0.86$ & 0.66 & $0.52,0.84$ & 0.64 & $0.45,0.92$ & 0.66 & $0.53,0.83$ & 0.66 & $0.46,0.93$ \\
\hline Dairy foods $(g / d)$ & $1 \cdot 10$ & $0.94,1.30$ & $1 \cdot 13$ & $0.88,1.45$ & $1 \cdot 12$ & $0.95,1.33$ & $1 \cdot 16$ & $0.90,1.50$ & 1.08 & $0.87,1.33$ & $1 \cdot 13$ & $0.81,1.57$ \\
\hline Cereals $(g / d)$ & 0.95 & $0.75,1.20$ & 0.85 & $0.58,1.23$ & 0.89 & $0.70,1.14$ & 0.79 & $0.54,1.16$ & 0.83 & $0.67,1.05$ & 0.79 & $0.55,1.13$ \\
\hline Meat $(\mathrm{g} / \mathrm{d})$ & 1.29 & $1.01,1.64$ & 1.36 & $0.93,1.98$ & $1 \cdot 21$ & $0.94,1.55$ & $1 \cdot 24$ & $0.84,1.84$ & 1.02 & $0.79,1.32$ & 1.04 & $0.70,1.56$ \\
\hline Fish $(g / d)$ & $1 \cdot 13$ & $0.99,1.30$ & $1 \cdot 14$ & $0.93,1.40$ & $1 \cdot 14$ & $1.00,1.31$ & $1 \cdot 17$ & $0.95,1.45$ & 1.08 & $0.94,1.26$ & 1.06 & $0.84,1.34$ \\
\hline Eggs $(g / d)$ & 1.08 & $0.91,1.29$ & 1.28 & $1.05,1.56$ & 1.07 & $0.89,1.27$ & 1.26 & $1.03,1.55$ & 1.02 & $0.85,1.23$ & 1.25 & $1.01,1.54$ \\
\hline Sugar and confectioneries (sweets) $(\mathrm{g} / \mathrm{d})$ & 0.82 & $0.65,1.03$ & 0.74 & $0.52,1.07$ & 0.82 & $0.65,1.04$ & 0.73 & $0.50,1.05$ & 0.83 & $0.65,1.05$ & 0.84 & $0.58,1.22$ \\
\hline Non-alcoholic beverages $(\mathrm{g} / \mathrm{d})$ & 1.09 & $0.88,1.36$ & 0.79 & $0.53,1.20$ & $1 \cdot 11$ & $0.88,1.39$ & 0.77 & $0.50,1.18$ & $1 \cdot 12$ & $0.90,1.40$ & 0.80 & $0.52,1.24$ \\
\hline Olive oil $(g / d)$ & 1.05 & $0.86,1.29$ & 1.37 & $0.98,1.91$ & $1 \cdot 10$ & $0.90,1.34$ & 1.42 & $1.02,1.96$ & & - & & - \\
\hline Saturated lipids $(\mathrm{g} / \mathrm{d})$ & 1.44 & $1.00,2.08$ & 1.54 & $0.87,2.71$ & 1.39 & $0.95,2.03$ & 1.46 & $0.80,2.65$ & 0.85 & $0.54,1.33$ & 0.79 & $0.38,1.64$ \\
\hline Monounsaturated lipids (g/d) & $1 \cdot 20$ & $0.88,1.64$ & 1.84 & $1.13,2.99$ & 1.25 & $0.92,1.70$ & 1.87 & $1 \cdot 16,3.01$ & 1.33 & $0 \cdot 78,2 \cdot 27$ & 1.46 & $0.62,3.41$ \\
\hline Polyunsaturated lipids (g/d) & $1 \cdot 12$ & $0.93,1.34$ & 0.89 & $0.64,1.23$ & 1.05 & $0.87,1.26$ & 0.82 & $0.59,1.14$ & $1 \cdot 16$ & $0.87,1.55$ & 0.94 & $0.58,1.53$ \\
\hline Monounsaturated:saturated lipid ratio & 0.95 & $0.84,1.08$ & 1.05 & $0.88,1.26$ & 0.98 & $0.86,1 \cdot 10$ & 1.07 & $0.89,1.27$ & 1.02 & $0.84,1.23$ & 1.04 & $0.78,1.38$ \\
\hline Energy intake $(\mathrm{kJ} / \mathrm{d})$ & 0.72 & $0.59,0.89$ & 0.73 & $0.53,1.00$ & 0.76 & $0.62,0.94$ & 0.80 & $0.58,1.10$ & & - & & - \\
\hline
\end{tabular}

*Age and energy intake entered in the model as continuous variables.

† Age, BMI, height, physical activity, years of schooling and energy intake entered as continuous variables. Alcohol consumption, smoking status and arterial blood pressure entered categorically in categories indicated in Tables 1 and 2 .

F Variables as entered in footnote $\dagger$, mutually adjusted for all variables in the table (entered per 1 standard deviation increment), except olive oil and energy intake that were not included in the model. For the monounsaturated:saturated lipid ratio values, the model was run without controlling for saturated and monounsaturated lipids. 
Given the number of associations evaluated in Tables 4 and 5, the results should be interpreted cautiously. Only with respect to meat among men (positive) and fruits and nuts among women (inverse) is there somewhat consistent evidence for an association with both the incidence of and mortality from CHD.

Table 6 shows overall and sex-specific hazard ratios for CHD incidence and mortality by level of conformity with the traditional MD as assessed through the MD score, both categorically and per two-point increment. Overall, increased conformity with the traditional $\mathrm{MD}$ was associated with a suggestive reduction in CHD incidence $(P=0 \cdot 115)$ and a statistically significant reduction in mortality $(P=0.003)$ from CHD. The results were generally more evident among women than among men and for CHD mortality rather than for CHD incidence. A two-point increase in the MD score was associated with a reduction in CHD mortality by $25 \%$ (95\% CI 0.57, 0.98) among women and 19\% (95\% CI 0.66, $0.99)$ among men.

To further probe the associations observed, we undertook a series of sensitivity analyses. In particular, we repeated the analysis presented in Table 6 focusing first on participants being overweight or obese (i.e. with BMI $\geq 25 \mathrm{~kg} / \mathrm{m}^{2}$ ) at baseline, since the MD has been reported to reduce the risk of obesity and the metabolic syndrome ${ }^{(32-34)}$. Second, events of angina without any revascularisation procedure were excluded from the incident CHD cases, in order to reduce possible misclassification bias in the outcome. Third, we excluded cases occurring in the first 2 years of follow-up to accommodate a possible longer latency. Lastly, to allow for possible changes in participants' diet over time, we only considered events occurring in the first 8 years after recruitment. No difference was evident when participants of normal weight at baseline were excluded. When cases of angina were excluded, the apparent effect of the MD on CHD incidence was somewhat more evident, particularly among men. When CHD deaths occurring in the first 2 years of follow-up were excluded, we found a stronger inverse association of the MD with CHD mortality, but only among women (for a two-point increase in the MD score, the HR changed from 0.75 to 0.69 ). When follow-up observations were censored at the 8th year, we noticed only among men a stronger inverse association between the MD score and CHD incidence (the HR changed from 0.98 to 0.96 , per two-point increment of the MD score) or CHD mortality (the HR changed from 0.81 to 0.76 for the same increment of the score).

\section{Discussion}

In a population-based cohort study of 23929 apparently healthy women and men in Greece, followed for a total of 229894 person-years for CHD incidence and 231725 personyears for CHD mortality, 636 incident cases of CHD and 240 deaths from this disease were recorded. After controlling for possible confounding influences by traditional non-nutritional risk factors for $\mathrm{CHD}$, conformity with the traditional MD, as operationalised through a widely used MD score, was significantly inversely associated with mortality from CHD and not 
significantly, but suggestively, associated with incidence of the disease. The inverse association with respect to both the incidence of and mortality from CHD was stronger among women than among men, possibly because women, the traditional housekeepers in Greece, have a better recollection and provide more accurate reporting of nutritional habits. In sensitivity analyses aiming to reduce misclassification of the diet during prolonged follow-up (more than 8 years), we found among men a somewhat stronger inverse association, whereas exclusion of deaths occurring during the first 2 years of follow-up resulted in stronger inverse associations among women. Of note, nutritional variables, including those that are part of the MD score, even after mutual adjustment, were inconsistently related to CHD incidence and mortality. Thus, the present results support the view that in the study of its association with health and disease, the traditional MD should be viewed and evaluated as an integral entity.

The present results are consistent with those of previous investigations evaluating individual dietary factors, as well as conformity with the MD in relation to CHD mortality and incidence $^{(35)}$. In an early study based on the Greek EPIC cohort, relying on a total of fifty-four CHD deaths, a two-point increase in the MD was associated with a significant decrease in CHD mortality by $33 \%{ }^{(4)}$. In a large American study, relying on the American Association of Retired Persons cohort, and including $3451 \mathrm{CVD}$ deaths, in comparison with those with low adherence ( $0-3$ units), those with high adherence (score 6-9 units) had significantly 22 and 19\% lower cardiovascular mortality, among men and women, respectively. In an analysis of data from the Nurses' Health Study, which included 2391 incident CHD cases and 794 CHD deaths, significant inverse trend associations were noted, with those in the fifth quintile having 29\% lower incidence and $42 \%$ lower mortality in comparison with those in the first (lowadherence) quintile. In the first analytical epidemiological study of adherence to the MD in relation to the incidence of CHD in a Mediterranean population, Spanish EPIC cohort participants with high adherence to the MD had a significant $40 \%$ lower risk of CHD in comparison with those with low adherence. Of note, in the Spanish study, only vegetables $(P=0 \cdot 01)$ and olive oil and alcohol $(P=0.05)$ were significantly inversely associated with CHD risk, even though the inverse association of the MD score with CHD was highly significant $(P<0 \cdot 001)$. In a recent publication based on the Spanish SUN Project cohort with 13609 participants with no prevalent CVD, who were followed for about 5 years, a two-point increment in a similar MD score was significantly associated with a $26 \%$ lower $\mathrm{CHD}$ risk $^{(22)}$. In a systematic review of prospective cohort studies or randomised trials investigating dietary exposures in relation to $\mathrm{CHD}$, evidence supported inverse associations for a limited number of dietary factors (notably vegetables, nuts and MUFA) with CHD risk. The MD pattern was the only dietary exposure with strong evidence of protection from both cohort and randomised trials ${ }^{(35)}$

A frequent misconception, which leads to a form of circular reasoning, is that the MD score assesses adherence to an a priori defined, 'optimal' health-protecting diet ${ }^{(4)}$. It should be clear that what the MD score assesses is adherence to the dietary pattern which was traditionally followed in the olive oil-growing areas of the Mediterranean up to the early $1960 \mathrm{~s}^{(36,37)}$; it just so happens that this traditional dietary pattern turned out to have favourable health effects. The key components of the traditional MD, including olive oil and wine, are plant-derived and the traditional MD is essentially a plant-derived diet which, however, does not dogmatically exclude meat or dairy products. In the present data, as in the data from the earlier study in a Mediterranean population $^{(21)}$, the MD scores tend to generate fairly consistent results with respect to $\mathrm{CHD}$, whereas results on their component foods or food groups were largely inconsistent. When a single food - rather than a multi-component, yet unidimensional, score - is evaluated, chance, non-differential misclassification and residual confounding may have more important consequences for several reasons. Chance is more likely to disruptively operate on a single food group rather than simultaneously on several components of a score. Moreover, in analyses focusing on individual components, effects are examined against the background of average risk associated with other nutritional components, whereas a dietary score can account for extremes of converging exposures with a minimal confounding influence of other major nutritional effects ${ }^{(4,38,39)}$.

The strengths of the present investigation are its cohort design, the use of a validated dietary evaluation instrument and reliance in a population where the MD has deep roots. An argument for the validity of the results is that traditional risk factors for CHD incidence and mortality were evident in the data. Limitations are the long interval between the assessment of exposure and outcome, allowing for possible changes in the diet that would lead to exposure misclassification and effect underestimation. When follow-up observations were censored at the 8th year to minimise the opportunity for changes in the diet, we noticed a stronger inverse association between the MD score and CHD events among men. The weak inverse associations observed, particularly in relation to adherence to the MD and CHD incidence among men, could be attributed to the use of a MD score which may not be nuanced enough to allow observing the differential effect of certain foods on the study outcome. Another limitation is that we have no information on blood cholesterol, which, however, can be thought of as an intermediate factor that does not necessarily require controlling for.

In conclusion, in a population in which the traditional MD has long-standing roots, we found that adherence to this diet is associated with a lower incidence of and mortality from CHD, a leading cause of death in most countries, including Greece. The traditional MD pattern could represent a feasible, easy to adhere to option for the preservation of coronary health.

\section{Acknowledgements}

This study was supported by the Hellenic Health Foundation, the Stavros Niarchos Foundation and the Greek Ministry of Health. P. L., A. N. and A. T. designed the study. V. D. conducted the study. M. K. performed the statistical analysis. 
V. D., P. L. and A. N. drafted the paper and all authors contributed in the development of the manuscript. A. T. had primary responsibility for the final content of the manuscript. D. T. was epidemiological consultant and A. T. is the principal investigator of the EPIC-Greece study. The authors declare that they have no conflicts of interest.

\section{References}

1. Keys A (1980) Seven Countries: A Multivariate Analysis of Death and Coronary Heart Disease. Cambridge: Harvard University Press.

2. Helsing E \& Trichopoulou A (1989) The Mediterranean diet and food culture - a symposium. Eur J Clin Nutr 43, Suppl. 2, 1-92.

3. Trichopoulou A, Kouris-Blazos A, Wahlqvist M, et al. (1995) Diet and overall survival in elderly people. BMJ 311, 1457-1460.

4. Trichopoulou A, Costacou T, Bamia C, et al. (2003) Adherence to a Mediterranean diet and survival in a Greek population. N Engl J Med 348, 2599-2608.

5. Fung TT, McCullough ML, Newby PK, et al. (2005) Dietquality scores and plasma concentrations of markers of inflammation and endothelial dysfunction. Am J Clin Nutr 82, 163-173.

6. Trichopoulou A, Orfanos P, Norat T, et al. (2005) Modified Mediterranean diet and survival: EPIC-elderly prospective cohort study. BMJ 330, 991.

7. Mitrou PN, Kipnis V, Thiébaut AC, et al. (2007) Mediterranean dietary pattern and prediction of all-cause mortality in a US population. Results from the NIH-AARP Diet and Health Study. Arch Intern Med 167, 2461-2468.

8. Lagiou P, Trichopoulos D, Sandin S, et al. (2006) Mediterranean dietary pattern and mortality among young women: a cohort study in Sweden. Br J Nutr 96, 384-392.

9. Sofi F, Abbate R, Gensini GF, et al. (2010) Accruing evidence on benefits of adherence to the Mediterranean diet on health: an updated systematic review and meta-analysis. Am J Clin Nutr 92, 1189-1196.

10. Fung TT, Rexrode KM, Mantzoros CS, et al. (2009) Mediterranean diet and incidence of and mortality from coronary heart disease and stroke in women. Circulation 119, 1093-1100.

11. Benetou V, Trichopoulou A, Orfanos P, et al. (2008) Conformity to traditional Mediterranean diet and cancer incidence: the Greek EPIC cohort. Br J Cancer 99, 191-195.

12. Fung TT, Hu FB, McCullough ML, et al. (2006) Diet quality is associated with the risk of estrogen receptor-negative breast cancer in postmenopausal women. J Nutr 136, 466-472.

13. Reedy J, Mitrou PN, Krebs-Smith SM, et al. (2008) Indexbased dietary patterns and risk of colorectal cancer: the NIH-AARP Diet and Health Study. Am J Epidemiol 168, 38-48.

14. Buckland G, Agudo A, Luján L, et al. (2010) Adherence to a Mediterranean diet and risk of gastric adenocarcinoma within the European Prospective Investigation into Cancer and Nutrition (EPIC) cohort study. Am J Clin Nutr 91, 381-390.

15. Trichopoulou A, Bamia C, Lagiou P, et al. (2010) Conformity to traditional Mediterranean diet and breast cancer risk in the Greek EPIC (European Prospective Investigation into Cancer and Nutrition) cohort. Am J Clin Nutr 92, 620-625.

16. Willett W (1998) Nutritional Epidemiology, 2nd ed., pp. 414-466. New York: Oxford University Press.

17. Knoops KT, de Groot LC, Kromhout D, et al. (2004) Mediterranean diet, lifestyle factors, and 10-year mortality in elderly
European men and women: the HALE project. JAMA 292, 1433-1439.

18. De Lorgeril M, Salen P, Martin J-L, et al. (1998) Mediterranean dietary pattern in a randomized trial: prolonged survival and possible reduced cancer rate. Arch Intern Med 158, 1181-1187.

19. Trichopoulou A, Bamia C \& Trichopoulos D (2005) Mediterranean diet and survival among patients with coronary heart disease in Greece. Arch Intern Med 165, 929-935.

20. Trichopoulou A, Bamia C, Norat T, et al. (2007) Modified Mediterranean diet and survival after myocardial infarction: the EPIC-elderly study. Eur J Epidemiol 22, 871-881.

21. Buckland G, González CA, Agudo A, et al. (2009) Adherence to the Mediterranean diet and risk of coronary heart disease in the Spanish EPIC Cohort Study. Am J Epidemiol 170, 1518-1529.

22. Martínez-González MA, García-López M, Bes-Rastrollo M, et al. (2011) Mediterranean diet and the incidence of cardiovascular disease: a Spanish cohort. Nutr Metab Cardiovasc Dis 21, 237-244.

23. Riboli E, Hunt KJ, Slimani N, et al. (2002) European prospective investigation into cancer and nutrition (EPIC): study populations and data collection. Public Health Nutr 5, 1113-1124.

24. Gnardellis C, Trichopoulou A, Katsouyianni K, et al. (1995) Reproducibility and validity of an extensive semiquantitative food frequency questionnaire among Greek school teachers. Epidemiology 6, 74-77.

25. Katsouyianni K, Rimm EB, Gnardellis C, et al. (1997) Reproducibility and relative validity of an extensive semiquantitative Food Frequency Questionnaire using dietary records and chemical markers among Greek school teachers. Int J Epidemiol 26, Suppl. 1, S118-SS27.

26. Trichopoulou A \& Georga K (2004) Composition Tables of Foods and Greek Dishes, 3rd ed. Athens: Parisianou Publications.

27. Ainsworth BE, Haskell WL, Leon AS, et al. (1993) Compendium of physical activities: classification of energy costs of human physical activities. Med Sci Sports Exerc 25, 71-80.

28. Trichopoulou A, Gnardellis C, Lagiou A, et al. (2000) Body mass index in relation to energy intake and expenditure among adults in Greece. Epidemiology 11, 333-336.

29. Psaltopoulou T, Orfanos P, Naska A, et al. (2004) Prevalence, awareness, treatment and control of hypertension in a general population sample of 26,913 adults in the Greek EPIC study. Int J Epidemiol 33, 1345-1352.

30. World Health Organisation (2006) International Statistical Classification of Diseases and Related Health Problems, 10th rev. Geneva: World Health Organization.

31. Misirli G, Bamia C, Dilis V, et al. (2012) Validation of selfreported incident cardiovascular disease events in the Greek EPIC cohort study. EBPH, (In the Press).

32. Romaguera D, Norat T, Vergnaud AC, et al. (2010) Mediterranean dietary patterns and prospective weight change in participants of the EPIC-PANACEA project. Am J Clin Nutr 92, 912-921.

33. Esposito K, Kastorini CM, Panagiotakos DB, et al. (2011) Mediterranean diet and weight loss: meta-analysis of randomized controlled trials. Metab Syndr Relat Disord 9, 1-12.

34. Salas-Salvadó J, Fernández-Ballart J \& Ros E (2008) Effect of a Mediterranean diet supplemented with nuts on metabolic syndrome status: one-year results of the PREDIMED randomized trial. Arch Intern Med 168, 2449-2458.

35. Mente A, de Koning L, Shannon HS, et al. (2009) A systematic review of the evidence supporting a causal link between dietary factors and coronary heart disease. Arch Intern Med 169, 659-669. 
36. Keys A, Aravanis E \& Sdrin H (1966) The diets of middle-aged men in two rural areas of Greece. Voeding 27, 575-586.

37. Kromhout D, Keys A, Aravanis C, et al. (1989) Food consumption patterns in the 1960s in seven countries. Am J Clin Nutr 49, 889-894.
38. Jacques PF \& Tucker KL (2001) Are dietary patterns useful for understanding the role of diet in chronic disease? $\mathrm{Am}$ J Clin Nutr 73, 1-2.

39. Trichopoulou A, Bamia C \& Trichopoulos D (2009) Anatomy of health effects of Mediterranean diet: Greek EPIC prospective cohort study. BMJ 338, b2337. 